\title{
Using longitudinal designs and online micro-narrative data to further our understanding of biography and the life course
}

\section{Oliver C. Robinson}

Commentary on: What autobiographical narratives tell us about the life course: Linking biographical and life-course research

Research into autobiographical narratives has produced a rich variety of methodologies across the social sciences. In her article in this issue, Hollstein expertly describes how the narrative interview developed by Schütze (2008), and analysis of data from it via the documentary method or narration analysis, illuminates the complex interdependencies of the life course. She presents the view, with which I agree, that while autobiographical narratives are embellished or selectively told for social purposes and are reliant on partial memories, they do contain factual content and some accurate recollections of the past. In this brief commentary, I consider whether longitudinal designs in biographical studies, and the use of "micro-narrative" data conveyed in social media, are means of moving towards a better understanding of how the creative combination of subjective and objective is formed in autobiographical narrative, and how this mix changes with age.

Hollstein briefly discusses the important role that longitudinal approaches to qualitative research can play in exploring the relationship of objectivity and subjectivity within the life story. In this vein, I recently conducted a longitudinal study of a single young adult individual (Mary) about her life after leaving university (Robinson, 2018). Over a period of four years, I gathered psychometric data on five occasions, gathered interview data twice (first after one year, and secondly after three years), and engaged in an online discussion towards the end of the study. Within the interviews and the online discussion, I presented Mary with extracts of her qualitative data from earlier phases of the study, and asked her for her retrospective interpretation of them. 
In the final interview with Mary, when presented with extracts from her first interview, she remarked how negative she had been then, and how unaware she was of that at the time. She made sense of this by portraying her evolving sense of self as becoming more conscious of various relational and social issues that she was cloistered from when at university and had become aware of, while developing and through the course of her life post-university. The overall narrative trajectory was therefore one of growing awareness and agency; of waking up into a more responsible and self-aware version of herself. What was clearly changing over time was the cognitive-affective overlay on the events of her life and the way in which the self was being authored and re-authored through these retrospective appraisals. A further suggested development to this methodology would be to get participants to produce two narratives of an event, separated by at least a year (or preferably two) in time, and then once both are transcribed, to read them and comment on their differences and what those differences mean.

Alongside longitudinal qualitative methods, a new frontier for life course research is studying the autobiographical narratives that are portrayed in social media and text messaging. Social media postings, emails and text messages that contain information about life events and experiences can be referred to as micro-narratives (Giles, 2017), or small stories (Georgakopoulou, 2017). Each tells a story, has an intended audience, a social purpose, and a selective focus that relates to context and medium. Small stories portrayed on social media are definable in being fragmented, open-ended, and mundane, yet show the hallmarks of narrative autobiographical self-presentation.

The representation of synchronous events and experiences sets small stories in social media apart from the retrospective accounts that have been typical of autobiographical narrative research in the past. Also, they are done in a shared space with additions and comments from others, such that most micro-narratives have an intersubjective element. 
Georgakpoulou (2014) finds that announcements of disruptions and negative affective stances typically lead to a small story with interpersonal co-constructive features.

A fruitful potential avenue for future investigation is to compare social media micronarratives written during a section of the life course or crisis, with a retrospective interviewbased narrative about the same part of the life story. Such an approach has the potential to provide insights into how much experiential content within retrospective accounts of a life story is a product of later employment and confabulation and how much of it reflects synchronous experiences and feelings from the time period being recollected.

One phenomenon of relevance in this area is the interdependence of transitions across life domains, which is very pronounced in retrospective interviews. For example, in describing a past crisis about transitions in job and relationships, it is common to narratively portray the events as (a) simultaneous and (b) resulting from the same essential motive (Robinson, Wright \& Smith, 2013), but this could be retrospective 'smoothing' of facts to ensure the telling of a coherent and compelling narrative. Comparing synchronous social media entries or text messages about the event can help establish if this kind of reconstructive "coherence-building" is an embellishment or an accurate representation of the events as they were reported in synchronous small stories.

In summary, as Hollstein rightly says, biographical narratives are a complex combination of subjective interpretation and objective fact about the life course. Future research, via longitudinal methods and micro-narrative online data, holds the promise of understanding this complex interaction further. In our age of constant online autobiographical story-telling, and the huge resource that presents to researchers, will interview-only studies of the life story soon be a thing of the past? Time will tell.

\section{References}


Georgakopoulou, A. (2014). Small stories transposition and social media: A microperspective on the 'Greek crisis'. Discourse and Society, 25, 519-539. DOI: https://doi.org/10.1177/0957926514536963

Georgakopoulou, A. (2017). Sharing the moment as small stories: The interplay between practices \& affordances in the social media-curation of lives. Narrative Inquiry, 27, 311-333. DOI: 10.1075/ni.27.2.06geo

Giles, D.C. (2017). How do fan and celebrity identities become established on Twitter? A study of 'social media natives' and their followers. Celebrity Studies, 8, 445-460.

Hollstein, B. (2018). What autobiographical narratives tell us about the life course: Linking biographical and life course research. Advances in Life Course Research, this issue.

Robinson, O.C. (2018). A longitudinal mixed-methods case study of quarter-life crisis in a university graduate: Locked-out and locked-in forms in combination. Emerging Adulthood, online first. DOI: 10.1177/2167696818764144

Robinson, O.C., Wright, G.R.T. \& Smith, J.A. (2013). The holistic phase model of early adult crisis. Journal of Adult Development, 20, 27-37. DOI: 10.1007/s10804-013-9153-y

Schütze, F. (2008). Biography Analysis on the Empirical Base of Autobiographical Narratives: How to Analyze Autobiographical Narrative Interviews - Part one and two, European Studies on Inequalities and Social Cohesion Nr. 1/2, pp. 153- 242, 243-298; 3/4, pp. 6-77. 